\title{
Can bending radiographs be useful for Lenke classification system of idiopathic scoliosis?
}

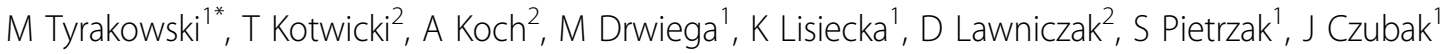 \\ From 9th International Conference on Conservative Management of Spinal Deformities - SOSORT 2012 \\ Annual Meeting \\ Milan, Italy. 10-12 May 2012
}

\section{Background}

Lenke classification of idiopathic scoliosis (IS) is based on standing ap and lateral radiographs, combined with assessment of scoliosis correction on bending X-rays.

\section{Aim}

The aim of this study was to verify the usefulness of bending films for Lenke classification of IS.

\section{Methods}

The radiographs of 30 consecutive patients operated on because of IS were examined. Seven independent researchers assessed the X-rays, in 3 stages at one week intervals.

Stage 1: Lenke type was determined on AP and lateral long film standing X-rays.

Stage 2: Lenke type was established by use of AP and lateral standing $\mathrm{X}$-rays, completed with supine traction films.

Stage 3: Lenke type was indicated using AP and lateral standing, supine traction, and lateral bending films.

The order of the radiographs, in each stage, was different and random. The results were determined by calculating the inter-observer and intra-observer agreement, and were quantified using two-rater and multi-rater kappa statistics.

\section{Results}

The inter-rater agreement in the first, and second, stage was moderate (multi-rater kappa coefficient: 0.41 in the first stage and 0.43 in the second stage; percentage agreement: 0.56 and 0.55 respectively). The inter-rater agreement in the third stage was less (multi-rater kappa coefficient: 0.34 and percentage agreement: 0.47 ). The intra-observer agreement was the highest between the first and second stage for each of the researchers (mean kappa coefficient: 0.69 ; mean percentage agreement: 0.76 ).

\section{Conclusions}

The use of lateral bending X-rays in classifying the IS, according to the criteria of Lenke, reduced the intra-rater and the inter-rater agreement. Supine traction radiographs of the spine improved the agreement. This may suggest that the supine traction X-rays may help in classifying the IS.

\section{Author details}

${ }^{1}$ Department of Orthopaedics, Pediatric Orthopaedics and Traumatology of Postgraduate Medical Education Centre in Warsaw, Poland. ${ }^{2}$ Spine Disorders Unit, Department of Pediatric Orthopedics and Traumatology, University of Medical Sciences, Poznan, Poland.

Published: 3 June 2013

\section{References}

1. Lenke LG, Betz RR, Bridwell KH, Clements DH, Harms J, Lowe TG, Shufflebarger HL: Intraobserver and interobserver reliability of the classification of thoracic adolescent idiopathic scoliosis. J Bone Joint Surg Am 1998, 80(8):1097-1106.

2. Lenke LG, Betz RR, Harms J, Bridwell KH, Clements DH, Lowe TG, Blanke K: Adolescent idiopathic scoliosis: a new classification to determine extent of spinal arthrodesis. J Bone Joint Surg Am 2001, 83-A(8):1169-1181.

3. Ward WT, Rihn JA, Solic J, Lee JY: A comparison of the lenke and king classification systems in the surgical treatment of idiopathic thoracic scoliosis. Spine (Phila Pa 1976) 2008, 33(1):52-60.

doi:10.1186/1748-7161-8-S1-O28

Cite this article as: Tyrakowski et al:: Can bending radiographs be useful for Lenke classification system of idiopathic scoliosis? Scoliosis 2013 8(Suppl 1):O28. 